\title{
Analisis Metode Identifikasi dan Verifikasi Kebutuhan Non Fungsional
}

\author{
Arizia Aulia Aziiza ${ }^{*}$, Asih Nur Fadhilah² \\ 1,2Jurusan Sistem Informasi, Institut Teknologi Sepuluh Nopember, Surabaya \\ *Corresponding Author \\ E-mail: ariziaauliaaziiza29@gmail.com*
}

\begin{abstract}
Abstrak
Kebutuhan non fungsional merupakan kebutuhan yang menggambarkan bagaimana sistem berkerja kedepannya. Dalam menentukan kebutuhan non fungsional tidaklah mudah, karena harus mengerti karakteristik dan batasan dari sistem. Terdapat beberapa permasalahan yang muncul ketika mengidentifikasikan kebutuhan non fungsional diantaranya ambiguitas, duplikasi, ketidakkonsistenan, definisi yang kurang, dan prioritas dari kebutuhan non fungsional yang kurang tepat. Oleh karena itu, diperlukannya cara untuk mengidentifikasi dan verifikasi kebutuhan non fungsional agar memudahkan dalam penentuan desain software untuk diimplementasikan oleh developer. Paper review ini melakukan analisis terhadap paper yang didapatkan dari database jurnal elektronik yaitu ScienceDirect dan IEEE dengan menggunakan kata kunci "non-functional requirement". Paper yang dianalisis dikelompokkan berdasarkan 5 tahun terakhir dan diklasifikasikan berdasarkan jenisnya, identifikasi atau verifikasi kebutuhan non fungsional. Hasilnya adalah metode yang sesuai untuk identifikasi dan verifikasi kebutuhan non fungsional. Metode yang sesuai untuk identifikasi kebutuhan non fungsional yaitu metode yang melakukan pengumpulan data kebutuhan terlebih dahulu. Sedangkan metode yang sesuai untuk verifikasi kebutuhan non fungsional yaitu pemodelan dan verifikasi kebutuhan non fungsional.
\end{abstract}

Kata Kunci: metode, identifikasi, verifikasi, kebutuhan non fungsional.

\begin{abstract}
Non-functional requirements are requirement that describe how the system works. Determining the non-functional requirements is not easy, because they must understand the characteristics and limitations of the system. There are several problems that arise when identifying non-functional requirement including ambiguity, duplication, inconsistency, lack of definition, and priorities that are not right. Therefore, the ways to identify and verify non-functional requirements is needed, in order to facilitate the determination of software design to be implemented by the developer. This review paper analyzes the paper obtained from electronic journal databases namely ScienceDirect and IEEE by using the keyword "non-functional requirements". The analyzed papers are grouped according to the last 5 years and are classified according to their type, identification or verification of non-functional requirements. The result is an appropriate method for identifying and verifying non-functional requirements. The method that is suitable for the identification of non-functional requirements is the method that collects the data needs first. While the appropriate method for verification of non-functional requirements is modeling and verification of non-functional needs.
\end{abstract}

Keywords: method, identification, verification, non-functional, requirement.

\section{PENDAhuluan}

Analisis kebutuhan merupakan tahapan yang sangat penting dalam pembangunan perangkat lunak, dikarenakan pada tahapan ini apabila terjadi kekeliruan dalam menggambarkan kebutuhan E-ISSN: 2621-4474, ISSN:2621-4458. 
sistem bisa mengakibatkan gagalnya sebuah proyek pembangunan perangkat lunak [1]. Kebutuhan diklasifikasikan sebagai kebutuhan fungsional (FR) dan kebutuhan non fungsional (NFR) [2].

Kebutuhan non fungsional (NFR) dapat dianggap sebagai kriteria dari kualitas atau kinerja yang harus dipenuhi oleh sistem perangkat lunak dan ini merupakan elemen kunci yang harus ditangani selama proses pengembangan [3]. Kebutuhan non fungsional (NFR) biasanya dibedakan dari kebutuhan fungsional dengan pembeda yaitu bagaimana sistem harus melakukan sesuatu yang bertentangan dengan apa yang harus dilakukan sistem [4]. Sedangkan Kebutuhan fungsional adalah kebutuhan yang menggambarkan apa yang akan dilakukan oleh sistem. Analisis hasil statistik dari penelitian Feng-Lin Li menunjukkan bahwa kualitas menjadi kunci antara kebutuhan non fungsional dalam praktik Requirement Engineering dan banyak kebutuhan yang diidentifikasi sebagai NFR sebenarnya merupakan FR [5] . Penentuan kebutuhan fungsional cenderung lebih mudah diidentifikasikan dibandingkan dengan penentuan kebutuhan nonfungsional dikarenakan kebutuhan fungsional digambarkan dengan fungsi-fungsi sistem sedangkan kebutuhan non fungsional lebih kepada karakteristik dan batasan dari sistem [6] [7].

Pada perangkat lunak yang berkualitas, perlu mempertimbangkan kebutuhan fungional (FR) dan kebutuhan non fungsional (NFR), kurangnya memperhatikan NFR menjadi penyebab kegagalan untuk banyak proyek perangkat lunak [8]. Kebutuhan non fungsional (NFR) meggambarkan kendala penting pada pengembangan dan perilaku perangkat lunak, hal ini harus dipertimbangkan diawal, jika tidak akan menyebabkan beberapa masalah pada produk akhir seperi ketidakstabilan dan kualitas yang rendah [9]. Kebutuhan non fungsional (NFR) dapat mengatasi masalah penting dalam sistem perangkat lunak, dan sangat penting dalam keberhasilkan perangkat lunak [3]. Masalah NFR dalam suatu sistem mencerminkan kompleksitas sistem tersebut, secara sistematis NFR diselifiki untuk menentukan aspek yang mungkin menyebabkan konflik yang harus dideteksi sedini mungkin [3]. Terdapat banyak kebutuhan non fungsional (NFR) yang ambigu, tidak memuaskan, duplikasi, ketidakkonsistenan, tidak jelas, dan subjektif, menunjukkan perlunya meta-kualitas dalam penentuan NFR [5].

Identifikasi dan verifikasi kebutuhan non fungsional menjadi hal yang penting dalam software requirement karena dengan detailnya kebutuhan non fungsional yang diperoleh, akan memudahkan penentuan desain software dan mudah untuk diimplementasikan oleh developer. Sayangnya identifikasi dan verifikasi kebutuhan non fungsional bukanlah hal yang mudah. Dengan menggunakan tinjauan pustaka kami menganalisis jurnal-jurnal yang membahas mengenai kebutuhan non fungsional untuk mengetahui: (i) apa saja model yang digunkan untuk identifikasi kebutuhan non fungsional, (ii) apa saja model yang digunkan untuk verifikasi kebutuhan non fungsional, dan (iii) model apa yang paling banyak digunakan, baik untuk identifikasi maupun untuk verifikasi kebutuhan non fungsional.

\section{METODOLOGI}

Pada bagian ini akan dijelaskan tentang hal-hal yang dilakukan dalam penelitian ini. Paper ini merupakan jenis paper summarize yang dihasilkan dari penggabungan hasil beberapa paper lainnya. Metode penelitian dan penyusunan paper ini terutama berfokus pada metode pengumpulan paper. Langkah-langkah yang dilakukan dalam penelitian ini adalah mencari paper, memilih paper, review paper, dan identifikasi karakteristik teknik elisitasi. Alur metodologi penelitian diperlihatkan pada Gambar 1. 


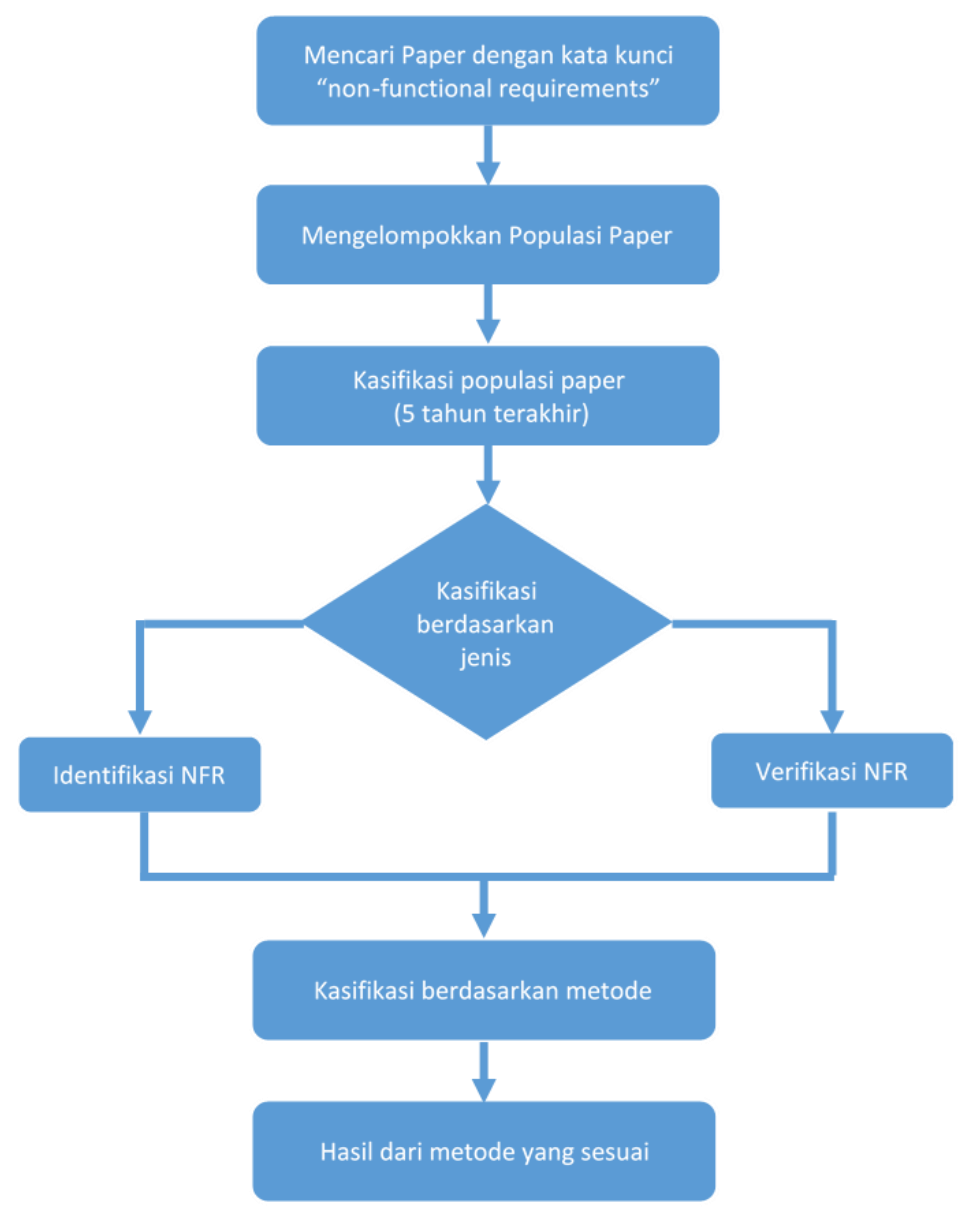

Gambar 1. Metodologi Penelitian

\subsection{Mencari paper}

Pada tahap ini dilakukan pencarian paper yang terkait dengan kebutuhan non fungsional. Untuk mendapatkan hasil paper yang terkait maka dilakukan dengan cara menggunakan kata kunci "non-functional requirement". Semua paper yang tersaring dari tahap ini akan dicatat dan dilakukan penyaringan kembali pada tahap selanjutnya.

\subsection{Mengelompokkan populasi paper}

Pada tahap ini dilakukan pengelompokan paper berdasarkan publikasinya dalam kurun waktu 5 tahun terakhir dan dikelompokkan berdasarkan tahun terbit paper. Populasi dimulai dari tahun 2014 hingga 2018.

\subsection{Mengklasifikasikan paper per tahun}

Berdasarkan hasil dari populasi pada tahap sebelumnya, dilakukan pengelompokan kembali paper setiap tahunnya. Pengelompokkan untuk mencari paper yang paling relevan dengan kebutuhan non-fungsional dengan menyaring berdasarkan judul publikasi yang terkait dengan "non-functional requirements". Untuk metode pengelompokkan populasi paper per tahun digunakan cara penyaringan data per-tahun, kemudian juga dilakukan pembandingan pencarian antara menggunakan command search dengan tanpa menggunakan command search. Command search adalah pencarian berdasarkan spesifik kata kunci dengan memberikan tanda kutip pada kata kunci pencarian paper. Dari proses ini menghasilkan jumlah paper yang akan dilakukan review. 


\subsection{Mengklasifikasikan paper berdasarkan jenisnya}

Dalam pengklasifikasian paper, sesuai dengan tujuan dari review paper yang diajukan yakni mengetahui cara mengidentifikasikan dan memverifikasi kebutuhan non fungsional. Maka klasifikasi paper dapat dibagi menjadi dua yakni berdasarkan kelompok identifikasi kebutuhan non fungsional, verifikasi kebutuhan non fungsional. Pengelompokkan ini dilakukan dengan cara menganalisis paper yang sudah didapatkan pada tahap sebelumnya.

\subsection{Mengklasifikasikan paper berdasarkan metodologi yang digunakan}

Setelah mengelompokkan paper berdasakan identifikasi dan verifikasi kebutuhan nonfungsional, maka dilakukan pengklasifikasian metode yang digunakan dalam paper tersebut. Klasifikasi metode ini bertujuan untuk mengetahui metode yang paling banyak digunakan oleh paper yang telah diperoleh. Metode tersebut dipilih untuk metode identifikasi dan verifikasi kebutuhan non fungsional yang paling sesuai, dan dijadikan sebagai hasil review paper ini.

\section{HASIL DAN PEMBAHASAN}

\subsection{Hasil}

Proses pencarian jurnal dimulai dengan pencarian jurnal pada database jurnal elektronik "ScienceDirect" dan "IEEE". Berdasarkan kata kunci "Non-Functional Requirement". Berdasarkan situs pencarian yakni ScienceDirect dan IEEE tanpa melakukan penyaringan tahun publikasi, didapatkan 1.501 paper pada ScienceDirect dan 1.272 paper pada IEEE. Kemudian proses berikutnya yakni mengelompokkan berdasarkan 5 tahun terakhir untuk tahun publikasinya. Hasil dari penyaringan yang ditunjukkan pada situs ScienceDirect terdapat 692 paper sedangkan pada IEEE terdapat 415 paper. Pengklasifikasian berdasarkan jenis mendapatkan sebanyak 34 paper, yang terdiri dari 8 paper dari ScienceDirect dan 26 paper dari IEEE. Hasil pengelompokan paper disajikan dalam bentuk grafik atau diagram yang berdasarkan topik pembahasan paper, metode yang digunakan, dan tahapan metodologi.

Pengelompokkan pertama didasarkan pada topik pembahasan. Terdapat tiga topik pada pengelompokan ini, yaitu identifikasi NFR, verifikasi NRP, dan keduanya. Setelah dilakukannya analisis didapatkan hasil bahwa paper yang membahas mengenai verifikasi memiliki jumlah yang lebih banyak dibandingkan dengan paper yang membahas identifikasi (Lihat Gambar 2).

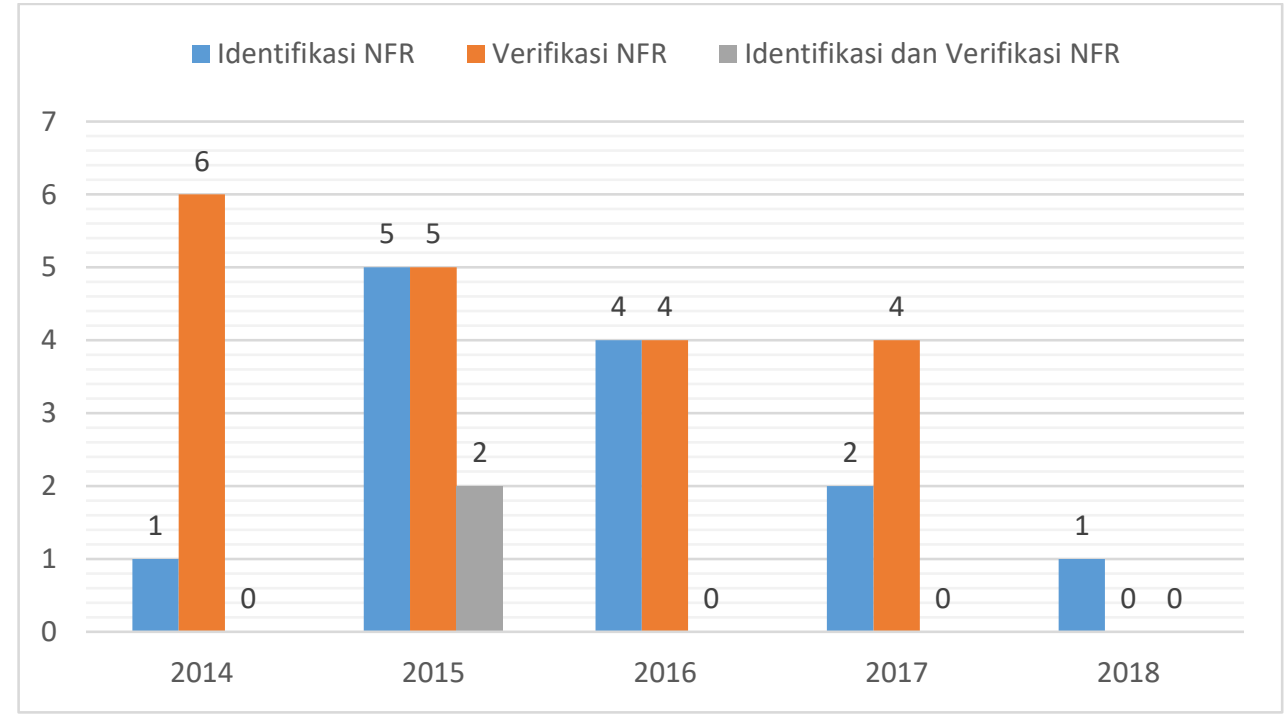

Gambar 2. Pengelompokkan Paper Berdasarkan Topik Pembahasan 
Paper yang membahas identifikasi kebutuhan non fungsinal berjumlah 13 paper, sedangkan paper yang membahas verifikasi kebutuhan non fungsinal sejumlah 19 paper, dan terdapat 2 paper yang membahas keduanya.

Pengelompokkan kedua didasarkan pada metode yang digunakan. Berdasarkan hasil review, terdapat banyak metode yang digunakan untuk melakukan identifikasi dan verifikasi kebutuhan non fungsional. Metode-metode tersebut dapat dikelompokkan seperti pada Tabel 1. Dapat dilihat bahwa pengelompokkan berdasarkan metode menghasilkan 14 metode identifikasi NFR dan 20 metode untuk verifikasi NFR. General Architecture for Text Learning (GATE) dan Java Annotation Patterns Engine (JAPE) merupakan metode identifikasi NFR yang digunakan dalam dua paper. Sedangkan untuk metode verifikasi, NFR modeling and verification adalah model yang digunakan pada 2 paper. Sementara itu, model yang lainnya, baik identifikasi maupun verifikasi hanya digunakan pada 1 jurnal.

Table 1. Pengelompokan Paper Berdasarkan Metode

\begin{tabular}{|c|c|c|c|}
\hline \multicolumn{2}{|l|}{ Identifikasi } & \multicolumn{2}{|l|}{ Verifikasi } \\
\hline Metode & Jumlah & Metode & Jumlah \\
\hline Ontological Interpretation & 1 & $\begin{array}{l}\text { NERV (NFR Elicitation, Reasoning and } \\
\text { Validating) Methodology }\end{array}$ & 1 \\
\hline Prosedur Multi-step & 1 & $\begin{array}{l}\text { Model Driven Engineering Techniques } \\
\text { menggunakan RELAX }\end{array}$ & 1 \\
\hline NORMAP dan NERV methodologi & 1 & HAM (Hybrid Assessment Method) & 1 \\
\hline NFR analysis Approach & 1 & $\begin{array}{l}\text { NFR Interdependency Framework } \\
(\text { NFRIF })\end{array}$ & 1 \\
\hline Modelling Method & 1 & Fuzzy-Bayesian Network & 1 \\
\hline $\begin{array}{l}\text { Latent Dirichlet Allocation (LDA) untuk } \\
\text { modeling NFR }\end{array}$ & 1 & NFR modeling and verification & 2 \\
\hline Model-based development & 1 & Tool chain & 1 \\
\hline $\begin{array}{l}\text { General Architecture for Text Learning } \\
\text { (GATE) dan Java Annotation Patterns } \\
\text { Engine (JAPE) }\end{array}$ & 2 & $\begin{array}{l}\text { DIVISE (DIscovery and Visual } \\
\text { Interactive } \\
\text { web Service Engine) }\end{array}$ & 1 \\
\hline $\begin{array}{l}\text { Supervised Machine Learning. Support } \\
\text { Vector Machine and Nä̈ve Bayes } \\
\text { Algorithms }\end{array}$ & 1 & Multi-stages Prosedur & 1 \\
\hline $\begin{array}{l}\text { Hybrid menggunakan traditional dan } \\
\text { agile methodologies }\end{array}$ & 1 & NFR Framework & 1 \\
\hline $\begin{array}{l}\text { JIT (Just-in-time) Requirement. Teknik } \\
\text { untuk modeling NFR menggunakan } \\
\text { Latent Dirichlet Allocation (LDA) }\end{array}$ & 1 & $\begin{array}{l}\text { IVEA (Indicator Optimization and rules } \\
\text { violation controlling evolutionary } \\
\text { algorithm) }\end{array}$ & 1 \\
\hline $\begin{array}{l}\text { HAZard and OPerability study } \\
(\text { HAZOP })\end{array}$ & 1 & $\begin{array}{lcr}\text { Ontological } & \text { Formalisation and } \\
\text { Automation } & \text { SIG } & \text { (Softgoal } \\
\text { Interdependency } & \text { Graph } & \end{array}$ & 1 \\
\hline $\begin{array}{l}\text { NERV (NFR Elicitation, Reasoning and } \\
\text { Validating) Methodology }\end{array}$ & 1 & $\begin{array}{l}\text { RDS (Requirement Description } \\
\text { Schema) }\end{array}$ & 1 \\
\hline $\begin{array}{l}\text { Model Driven Engineering Techniques } \\
\text { menggunakan RELAX }\end{array}$ & 1 & $\begin{array}{l}\text { CDNFRE (Conflict Detector in Non } \\
\text { Functional Requirements) } \\
\text { menggunakan ontology }\end{array}$ & 1 \\
\hline & & cost-value proritization technique & 1 \\
\hline
\end{tabular}




\begin{tabular}{|l|c|}
\hline $\begin{array}{l}\text { (Multi Criteria Decision Analysis) } \\
\text { MCDA-based method }\end{array}$ & 1 \\
\hline $\begin{array}{l}\text { Extending the Requirement Frame } \\
\text { Model }\end{array}$ & 1 \\
\hline $\begin{array}{l}\text { Model Drive Software Engineering } \\
\text { MDSE) }\end{array}$ & 1 \\
\hline NFR prioritization & 1 \\
\hline $\begin{array}{l}\text { NFR Design and Rational (NDR) } \\
\text { Framework. }\end{array}$ & 1 \\
\hline
\end{tabular}

Hasil pengelompokkan yang didasarkan pada metode yang digunakan masih terlalu luas untuk menjawab rumusan masalah yang diajukan. Oleh karenanya, pengelompokkan ketiga dilakukan dengan dasar tahapan dari masing-masing metode. Pada metode identifikasi NFR, melakukan pengumpulan data kebutuhan terlebih dahulu merupakan tahapan yang paling banyak digunakan dalam model yang ditemukan. Tahapan tersebut digunakan pada beberapa model, yakni ontologi [5], semantik [10], Optical Character Recognition (OCR) [11], analysis approach [12], Machine Learning [6] dan terakhir menggunakan NERV [8]. Melalui metode tersebut, dilakukan analisis terhadap pengelompokan yang telah dihasilkan, dan kemudian dihasilkan NFR yang berkualitas. Hasil pengelompokan metode identifikasi kebutuhan non fungsional secara keseluruhan dapat dilihat pada Tabel 2. Sedangkan untuk metode verifikasi NFR, NFR modeling and verification merupakan tahapan yang paling banyak digunakan. Kebutuhan non fungsional yang sudah ada dimodelkan dengan pendekatan tertentu untuk selanjutnya dilakukan proses verifikasi. Metode ini digunakan oleh lima paper dengan pendekatan yang bebeda namun memiliki tahapan yang hampir sama. Metode yang menggunakan tahapan tersebut adalah NFR modeling and verification [7], NFR modeling [13], (Multi Criteria Decision Analysis) MCDA-based method [14], Model Driven Engineering Techniques menggunakan RELAX [15], dan Model Drive Software Engineering (MDSE) [16].

\subsection{Pembahasan}

Dalam lima tahun terakhir pembahasan mengenai kebutuhan non fungsional menjadi topik yang cukup banyak dilakukan oleh para peneliti dan praktisi yakni terdapat 34 paper yang membahas kebutuhan non fungsional. Dari paper yang didapatkan, dapat dikelompokkan dalam identifikasi kebutuhan non fungsional dan verifikasi kebutuhan non fungsional.

Berdasarkan pengelompokkan tersebut terdapat 15 metode yang digunakan dalam identifikasi kebutuhan non fungsional. Sedangkan untuk verifikasi kebutuhan non fungsional terdapat 21 metode seperti yang ditunjukkan pada Tabel 1. Berdasarkan hasil tersebut dapat dilihat bahwa pembahasan terkait verifikasi kebutuhan non fungsional lebih banyak diteliti. Hal ini dikarenakan permasalahan dalam requirement engineering adalah sulitnya menentukan kebutuhan non fungsional [5], terabaikannya kebutuhan non fungsional pada tahapan requirement engineering [11] [2] [8], dan kesalahan penafsiran dalam penerapan kebutuhan non fungsional pada sistem [17]. Literatur menunjukkan bahwa fungsi adalah fokus utama dalam proses Agile. Sementara kebutuhan non-fungsional (NFR) diabaikan atau tidak jelas [8]. Padahal kebutuhan nonfungsional (NFR), seperti reusabilitas, lebih lanjut memainkan peran penting dalam perangkat lunak dan rekayasa sistem [2]. Memodelkan NFR adalah metode yang efisien untuk analisis dan desain segala system [13]. Disisi lain, verifikasi desain model bisa mengurangi resiko pembangunan atas kualitas produk yang rendah [7]. Selain itu, harus ada cara untuk 
memverifikasi kebutuhan ini sedini mungkin, bahkan sebelum pengembangan sistem ini dimulai [15]. Berdasarkan beberapa alasan tersebut, memodelkan kebutuhan non fungsional menjadi metode yang kebanyakan dilakukan oleh para peneliti.

Tantangan lain untuk verifikasi kebutuhan adalah keterbatasan biaya dan waktu, seorang developer harus memutuskan kebutuhan mana yang mengarah kepada kepuasan pemangku kepentingan. Untuk mengatasi permasalahan ini diperlukan prioritas terhadap kebutuhan [18]. NFRs sering bergantung satu sama lain dan hubungan mereka dapat mempengaruhi kualitas perangkat lunak. NFR cenderung konflik, mengganggu dan bertentangan satu sama lain. Sulit untuk menangani interdependensi karena kebutuhan bisa sangat kompleks [19]. Dari beberapa tantangan tersebut beberapa peneliti mengajukan metode prioritas NFR dan deteksi konflik untuk mengatasinya.

Akan tetapi dari alasan-alasan diatas bukan berarti bahwa proses identifikasi menjadi hal yang tidak penting dalam penentuan kebutuhan non fungsional. Sebagai asumsi meskipun kebutuhan tersebut secara explisit tidak didefinisikan, kebutuhan non fungsional cenderung tertanam dalam kebutuhan fungsional [10]. Secara umum, tujuan yang diperoleh dari para pemangku kepentingan tidak jelas, ambigu, ideal, dll [5]. Secara eksplisit mengidentifikasi NFR pada awal proses perangkat lunak sangat penting untuk membuat keputusan desain awal, dan kemudian untuk mengevaluasi alternatif arsitektur untuk sistem [10]. Dalam Rekayasa Perangkat Lunak, kebutuhan Fungsional (FRs) lebih diutamakan dan kebutuhan Non-Fungsional (NFR) diabaikan hingga tahap akhir pengembangan perangkat lunak. Pengembang perangkat lunak lebih memperhatikan kebutuhan fungsional perangkat lunak yang memenuhi kebutuhan bisnis, dan NFR seperti kinerja, kegunaan, keandalan, keamanan, dan skalabilitas biasanya ditangani kemudian selama fase pengujian sistem [11]. Hal-hal tersebut cukup memberikan alasan bahwa identifikasi kebutuhan non fungsional juga penting dilakukan pada saat melakukan Requiremnet Enginering. Tetapi metode apakah yang paling tepat untuk menentukan kebutuhan non fungsional. Metode dengan tahapan awal pengumpulan semua kebutuhan baik kebutuhan fungsional maupun kebutuhan non fungsional merupakan metode yang paling banyak dilakukan. Dikarenakan pengumpulan kebutuhan juga merupakan fase awal dari proses Requiremnet Enginering.

\section{KESIMPULAN}

Berdasarkan pada hasil literatur review, diperoleh beberapa kesimpulan diantaranya bahwa pada penelitian ini terdapat 14 model untuk identifikasi kebutuhan non fungsional berdasarkan 15 paper yang ditemukan. Sedangkan pada verifikasi, terdapat 20 model untuk verifikasi kebutuhan non fungsional berdasarkan 21 paper yang ditemukan. Pada tahapan yang paling banyak digunakan pada metode identifikasi kebutuhan non fungsional adalah melakukan pengumpulan data kebutuhan terlebih dahulu berdasarkan 6 paper. Sedangkan pada tahapan yang paling banyak digunakan untuk metode verifikasi kebutuhan non fungsional adalah NFR modeling and verification berdasarkan 5 paper.

\section{DAFTAR PUSTAKA}

[1] K. Khatter dan A. Kalia, "Quantification of Non-functional Requirements," Shimla, 2014.

[2] J. Eckhardt, D. M. Fernández dan A. Vogelsang, "How to specify Non-functional Requirements to support seamless modeling?," dalam IEEE, München, Germany, 2015. 
[3] H. Hu, Q. Z. T. Ma, Y. Tan, H. Xiang, C. Fu dan Y. Feng, "Semantic modelling and automated reasoning of non-functional requirement conflicts in the context of softgoal interdependencies," IET Software, vol. 9, pp. 145-156, 2015.

[4] J. Eckhardt, A. Vogelsang dan D. M. Fernández, "Are "Non-functional" Requirements really Non-functional?," dalam 38th IEEE International Conference on Software Engineering, München, Germany, 2016.

[5] F.-L. Li, J. Horkoff, J. Mylopoulos dan A. Borgida, "Non-functional Requirements as Qualities, with a Spice of Ontology," dalam IEEE, Sweden, 2014.

[6] Z. Kurtanovic dan W. Maalej, "Automatically Classifying Functional and Non-Functional Requirements Using Supervised Machine Learning," dalam IEEE 25th International Requirements Engineering Conference, Hamburg, Germany, 2017.

[7] F. Z. Hammani, "Survey of Non-Functional Requirements Modeling and Verification of Software Product Lines," dalam IEEE, Morocco, 2014.

[8] D. Domah dan F. J. Mitropoulos, "The NERV Methodology: A Lightweight Process for Addressing Non-functional Requirements in Agile Software Development," dalam Proceedings of the IEEE SoutheastCon, Fort Lauderdale, Florida, 2015.

[9] J. Zou, L. Xu, M. Yang, X. Zhang dan D. Yang, "Towards comprehending the nonfunctional requirements through Developers' eyes: An exploration of Stack Overflow using topic analysis," Information and Software Technology, vol. 84, pp. 19-32, 2017.

[10] A. Mahmoud, "An Information Theoretic Approach for Extracting and Tracing Nonfunctional Requirements," dalam IEEE, Baton Rouge, LA, 2015.

[11] R. R. Maiti dan F. J. Mitropolus, "Capturing, Eliciting, Predicting and Prioritizing (CEPP) Non-Functional Requirements Metadata During the Early Stages of Agile Software Development," dalam Proceedings of the IEEE SoutheastCon, Fort Lauderdale, Florida, 2015.

[12] B. M. Aljallabi dan A. Mansour, "Enhancement Approach for Non-Functional Requirements Analysis in Agile Environment," dalam International Conference on Computing, Control, Networking, Electronics and Embedded Systems Engineering, Khartoum, Sudan, 2015.

[13] F. Z. Hammani, M. Rhanoui dan B. El-Asri, "Towards a Variable Non-Functional Requirements Integration for Component-Based Product Line," dalam IEEE, Morocco, 2014.

[14] L. H. G. Paucar dan N. Bencomo, "The Reassessment of Preferences of Non-Functional Requirements for Better Informed Decision-making in Self-Adaptation," dalam IEEE 24th International Requirements Engineering Conference Workshops, UK, 2016.

[15] M. Ahmad, N. Bellior dan J.-M. Bruel, "Modeling and verification of Functional and NonFunctional Requirements of ambient Self-Adaptive Systems," The Journal of Systems and Software, vol. 107, pp. 50-70, 2015.

[16] F. Khalique, W. H. Butt dan S. A. Khan, "Creating Domain Non-Functional Requirements in Software Product Line Engineering using Model Transformations," dalam International Conference on Frontiers of Information Technology, Islamabad, Pakistan , 2017.

[17] S. Kopczynsk dan J. Nawrocki, "HAZOP-based Approach to Pattern Identification for Nonfunctional Requirements," dalam IEEE, Poznan, Poland, 2015.

[18] M. Dabbagh, S. P. Lee dan R. M. Parizi, "Application of Hybrid Assessment Method for Priority Assessment of Functional and Non-functional Requirements," Malaysia, 2014.

[19] M. R. Tabassum, M. S. Siddik, M. Shoyaib dan S. M. Khaled, "Determining Interdependency Among Non-functional Requirements to Reduce Conflict," dalam 3rd International Conference on Informatics, Electronics \& Vision, Dhaka, 2014. 
[20] N. A. Muhammad, "Pembuatan Aplikasi Presensi Perkuliahan Berbasis Fingerprint (Studi Kasus : Jurusan Sistem Informasi Institut Teknologi Sepuluh Nopember Surabaya)," JURNAL TEKNIK POMITS Vol. 2, No. 3, (2013) ISSN: 2337-3539 (2301-9271 Print), 2013.

[21] R. P. Wibowo, Interviewee, Kesiapan Penerapan Absensi berbasis Fingerprint Mahasiswa JSI-ITS. [Wawancara]. 5 December 2014.

[22] M. Levinson, When Failure is Not Option, Framingham, (2006).

[23] A. Subiyakto, "Manajemen Perubahan dalam Pengembangan Sistem Informasi Perguruan Tinggi," 2000.

[24] B.P. Lientz dan K.P. Rea, Breakthrought IT Change Management, USA: Elseiver Butterwoth Heinemann, 2004.

[25] R. D. Gunawan, R. R. Suryono dan I. Purwanto, "Analisa Perubahan Manajemen dalam implementasi SI/TI pada Perguruan Tinggi ABC," Lampung, 2010.

[26] D. Anderson dan L.A. Anderson, Beyond Change Management: Advanced Strategies for Todays transformational Leaders, USA: Jossey-Bass, 2001.

[27] "Overview:ADKAR," 2014. [Online]. Available: http://www.changemanagement.com/tutorial-adkar-overview-mod2.htm. [Diakses 1 December 2014].

[28] A. H. N. Ali, E. W. T. Darmaningrat dan D. D. Winardi, "Change Management Strategies of E-Learning Adoption In Secondary Schools: A Case Study of Public Junior High Schools in Surabaya," dalam ICEEL, Bali, 2018.

[29] G. Xiong, "Change Management on Improvement Project for Success," pp. 13-16, 2016. 